\title{
Three-Dimensional Modal Analysis of Brezina Concrete Arch Dam, Algeria
}

\author{
Amina Tahar Berrabah ${ }^{1}$, Mohamed Belharizi ${ }^{2}$, André Laulusa ${ }^{3} \&$ Abdelmalek Bekkouche ${ }^{1}$ \\ ${ }^{1}$ Department of Civil Engineering, Aboubekr Belkaid University, Tlemcen, Algeria \\ ${ }^{2}$ Consultant, 37 impasse Armand, 92160 Antony, France \\ ${ }^{3}$ Soditech Ingénierie, 1 bis Allée des Gabians, 06150 Cannes La Bocca, France \\ Correspondence: Amina Tahar Berrabah, Department of Civil Engineering, Aboubekr Belkaid University, 13000 \\ Tlemcen, Algeria. Tel: 213-697-826-043. E-mail: tb_amina@hotmail.com
}

Received: January 29, 2012 Accepted: February 14, 2012 Online Published: June 5, 2012

doi:10.5539/esr.v1n2p55 URL: http://dx.doi.org/10.5539/esr.v1n2p55

\begin{abstract}
In this paper, modal responses of the Brezina concrete arch dam, Algeria, are determined using the finite elements commercial packages ANSYS. To study the effects of the foundation soil, three 3D models have been created, the dam alone without soil, the dam-massless soil and the dam-soil with soil mass model. Moreover, a parametric study of the viscous damping, in Raleigh form, has been conducted. It is found that the natural frequencies of either undamped or damped modes obtained from the dam-soil with soil mass model are drastically lower compared to that of the dam alone model, and are markedly lower than those obtained from the dam-massless soil model. Likewise, similar comparisons have been observed for the damping quantities, in absolute values, between the three models. An in-depth review of the literature reveals that the study carried out herein constitutes several elements of originality as only very few similar work have been undertaken.
\end{abstract}

Keywords: modal analysis, concrete dam, viscous damping, QR damped method

\section{Introduction}

The seismic response of an engineering structure is affected by the medium on which it is founded (Dimitri et al., 2008). It is now generally known that the foundation soil significantly affects the dynamic response of gravity dam during earthquakes (Bayraktar et al., 2005). Structural response is then governed by the interplay between the characteristics of the soil, the structure and the input motion. Soil-Structure Interaction (SSI), as this phenomenon has become known, has been of research interest for the past 30 years (Dimitri et al., 2008).

In the literature, there are four different modeling of the foundation soil: the standard rigid-base model, the massless-foundation model, the deconvolved-base-rock model, and the free-field dam-foundation interface model (Leger \& Boughoufalah, 1989). In the massless foundation model, absence of mass makes the foundation rock as a spring, i.e., only the flexibility of the foundation rock is taken into account. Theoretically, to take advantage of the dam's geometrical characteristics and loading conditions, most structural analyses performed on the dam-foundation soil system are based on the 2D plane strain assumption.

The primary energy loss mechanism currently assumed in the analysis of concrete dams is viscous damping (Tepes et al., 2010). Equivalent viscous damping constants have been determined experimentally. Shaking tests using low-level excitations have been performed on concrete dams throughout the world, and damping ratio of 2 to 5 percent of the critical damping have been reported (Dreher, 1980). However, damping ratio as high as 10 percent of the critical damping has been measured during higher levels excitations. Therefore, a damping ratio of 2 to 10 percent appears reasonable for most concrete dams (Dreher, 1980).

It is well known that real modes, which are obtained assuming free natural vibrations without damping, can be used as a modal base in a modal superposition analysis, e.g. a spectrum analysis, where damping is small. However, for structures exhibiting significant viscous damping, for example a damping ratio of 5 percent, real modes might not be appropriate. In this case complex modes should be employed rather (Ansys theory manual, 2007).

In this paper, influence of the foundation soil on the modal response of the Brezina arch dam-foundation soil, 
located in El Beyadh, Algeria, is investigated. Moreover, a parametric study of the damping ratio is conducted. Following this section, three dam-foundation soil finite element models are presented in Section 2. Undamped modal analysis results are reported in Section 3. Section 4 covers damped modal analysis results. Conclusions are offered in the last section of the paper.

\section{Dam-foundation Soil Finite Element Models}

Due to the arch shape of the Brezina dam, it is inappropriate to assume 2D plane strain conditions, see Figure 1. The dam is located in El Beyadh, in the west of Algeria. The dam is $60 \mathrm{~m} \mathrm{high,} \mathrm{its} \mathrm{maximum} \mathrm{arch} \mathrm{length} \mathrm{is} 78.5$ $\mathrm{m}$ and its thickness varies from $5 \mathrm{~m}$ at the crest to $36.3 \mathrm{~m}$ at the foundation level.

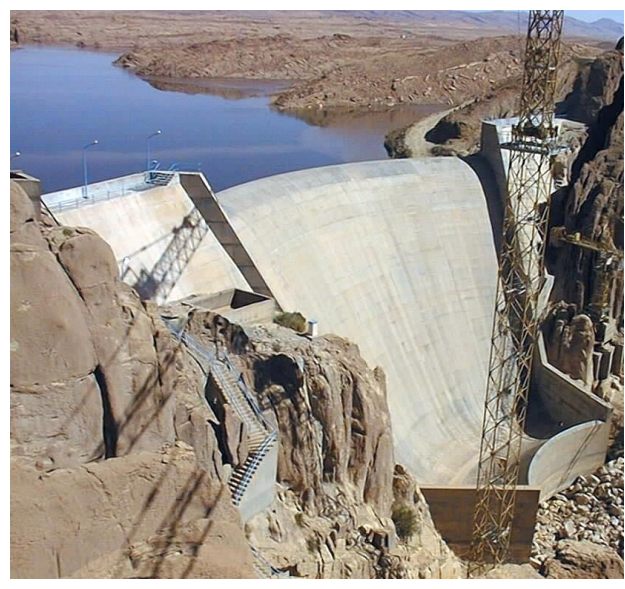

Figure 1. Brezina concrete arch dam

The dam-foundation soil structure is investigated using three 3D finite element models. The first model or dam alone, neglecting the soil, represents the dam only, which is clamped at its base on the soil, see Figure 2a. The second model or dam-massless soil, represents the dam and the adjacent soil but the soil's mass is neglected. The soil is also clamped at its base, see Figure 2b. Lastly, the third model or dam-soil with soil mass, is similar to the second one, except that the mass of the soil is taken into account (Figure 2b). These finite elements models are created using the finite element commercial package, ANSYS, with a mapped meshing (Ansys theory manual, 2007). The finesse of the mesh has been determined by performing a convergence analysis (mesh sensitivity). ANSYS is one of the leading commercial finite element programs in the world and can be applied to a large number of applications in engineering, it performs linear and nonlinear analyses; nevertheless it is not specialized for SSI analysis. Another objective of the present work is to orient this finite element code to the treatment of soil structure interaction problems.
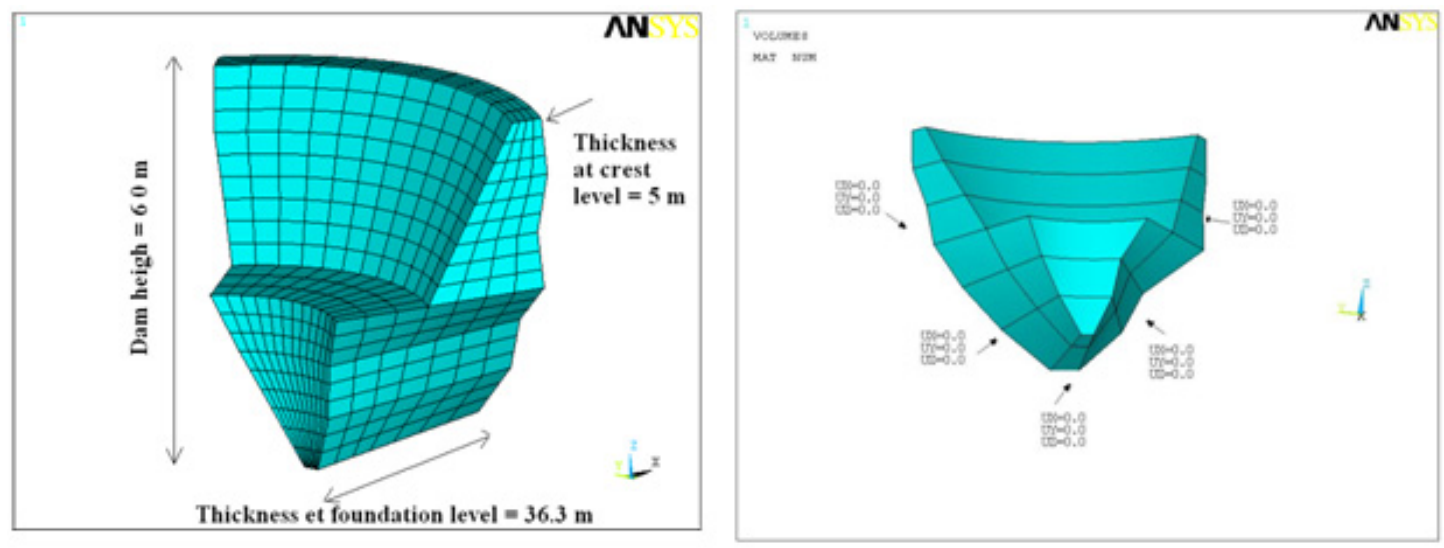

Figure 2a. 3D finite element model of Brezina arch dam without adjacent soil and boundary conditions 

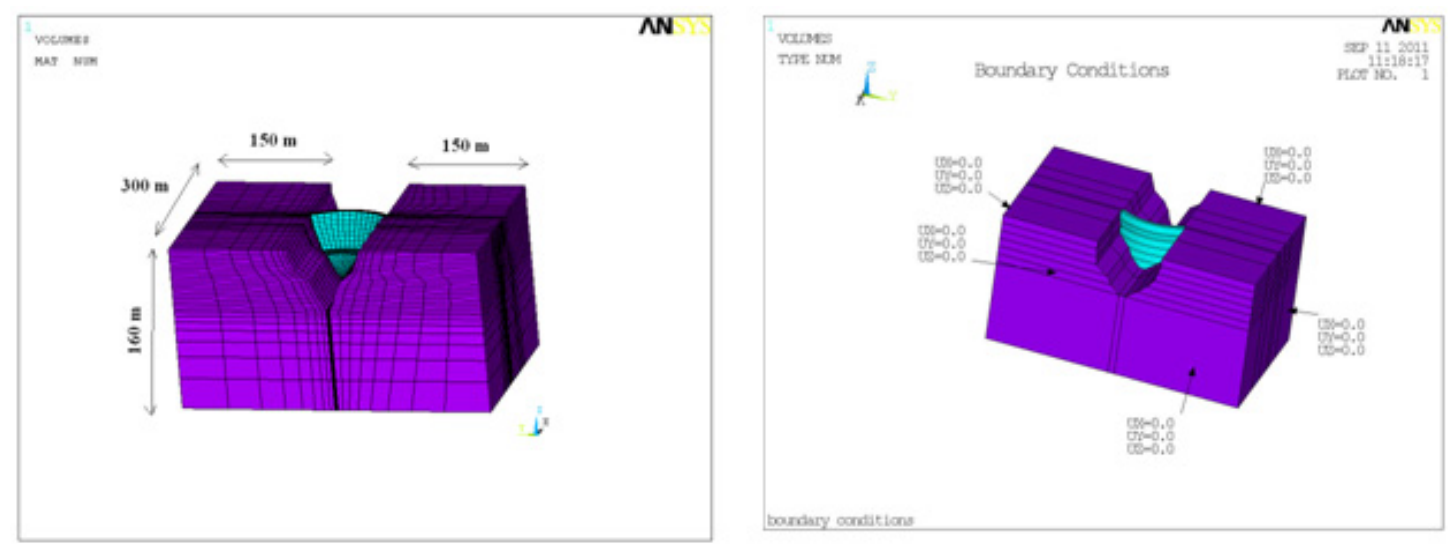

Figure 2b. 3D finite element model of Brezina arch dam with adjacent soil and boundary conditions

The first model, i.e., dam alone, possesses 972 quadratic solid elements (SOLID185) and 1378 nodes (Figure 2a). The second and third model (with the soil) exhibits 16252 quadratic solid elements and 19035 nodes (Figure 2b).

The length and width of the soil, along the global $\mathrm{X}$ and $\mathrm{Y}$ axis, respectively, are taken to be $150 \mathrm{~m}$, while its depth, along the $\mathrm{Z}$ direction, is taken to be $100 \mathrm{~m}$. These sizes are chosen so that the applied boundary condition will not affect the modal responses of the dam.

The material properties for both the concrete arch dam and foundation soil are reported in Table 1. These characteristics are provided by a governmental organism in charge of the dam study and from the geotechnical rapport of Brezina dam site.

Table 1. Material properties of Brezina dam

\begin{tabular}{llll}
\hline Material & Young's Modulus $\left(\mathrm{N} / \mathrm{m}^{2}\right)$ & Poisson's ratio & Density $\left(\mathrm{kg} / \mathrm{m}^{3}\right)$ \\
\hline Concrete dam & $28.5 \mathrm{e}+09$ & 0.2 & 2500 \\
Foundation soil & $14.5 \mathrm{e}+09$ & 0.25 & 2100 \\
\hline
\end{tabular}

\section{Undamped Modal Analysis Results}

This section covers undamped modal responses of the Brezina arch dam-foundation soil system. The modal responses are calculated using the Block Lanczos method (Ansys theory manual, 2007). Reported quantities are the first natural mode frequencies and the corresponding participation factor, Pfi along X direction, its ratio to the maximum participation factor, Ratio and effective mass, Mei. Table 2, Table 3 and Table 4 list these quantities for the dam alone, dam with massless soil, and dam-soil with soil mass, respectively (results are along $\mathrm{X}$ direction). The number of modes reported is such that the ratio of the cumulative effective mass to the total mass reaches a minimum of 0.9 along each of the three, $\mathrm{X}, \mathrm{Y}$ and $\mathrm{Z}$ directions. Quantities along $\mathrm{Y}$ and $\mathrm{Z}$ direction are omitted herein.

The fundamental mode is defined as the one that involves the maximum mass, i.e., the most dominant mode having a ratio, Ratio of one for the direction considered (here along $\mathrm{X}$ direction).

As expected, the highest frequencies are obtained from the dam alone model (Table 2) while the lowest ones are due to the dam-soil with soil mass (Table 4). Qualitatively, these results can be explained with the single degree of freedom mass-spring system for which the circular frequency is:

$$
\omega=\sqrt{\frac{\mathrm{k}}{\mathrm{m}}}
$$

where $\mathrm{k}$ is the stiffness of the spring and $\mathrm{m}$ the mass (Shabana, 1995). With respect to the dam alone model, the dam-massless soil has the same total mass, but is globally less rigid since the soil's Young's modulus is almost half the value of that of the concrete dam (see Table 1), thus from Equation (1), lower frequencies are obtained from the latter model. Also, between the dam-massless soil and dam-soil with soil mass, the global stiffness is identical but the total mass is evidently larger for the dam-soil with soil mass, hence, again from Equation (1), 
lower frequencies are obtained from the latter model. It is worth noting that the position of the fundamental mode is unchanged from the dam alone to the dam-massless soil model (mode number one of Table 2 and 3), while it switches to the fourth position when the mass of the soil is taken into account (Table 4).

Table 2. Dam alone first undamped natural frequencies in $X$ direction

\begin{tabular}{lllll}
\hline Mode & Frequency $(\mathrm{Hz})$ & $\mathrm{P}_{\mathrm{fi}}$ & Ratio & Mei $(\mathrm{Kg})$ \\
\hline 1 & 12.42 & 5548.5 & 1.00000 & $0.3078 \mathrm{e}+08$ \\
2 & 18.56 & -14.827 & 0.00267 & 219.850 \\
3 & 24.83 & -5402.2 & 0.97363 & $0.2918 \mathrm{e}+08$ \\
4 & 26.53 & 3259.9 & 0.58753 & $0.1062 \mathrm{e}+08$ \\
5 & 27.80 & -195.93 & 0.03531 & 38388.0 \\
6 & 30.37 & -1909.8 & 0.34419 & $0.3647 \mathrm{e}+07$ \\
7 & 33.17 & -143.98 & 0.02595 & 20730.7 \\
8 & 35.86 & 190.59 & 0.03435 & 36323.9 \\
9 & 38.56 & 4063.6 & 0.73238 & $0.1651 \mathrm{e}+08$ \\
10 & 44.41 & -1961.4 & 0.35350 & $0.3847 \mathrm{e}+07$ \\
11 & 44.74 & 1253.8 & 0.22596 & $0.1571 \mathrm{e}+07$ \\
12 & 46.51 & 331.38 & 0.05972 & 109814. \\
13 & 48.04 & 1684.0 & 0.30349 & $0.2835 \mathrm{e}+07$ \\
14 & 49.02 & -836.08 & 0.15068 & 699027. \\
15 & 51.22 & 160.33 & 0.02889 & 25706.9 \\
16 & 51.46 & -1437.2 & 0.25902 & $0.2065 \mathrm{e}+07$ \\
17 & 53.00 & -2126.5 & 0.38326 & $0.4522 \mathrm{e}+07$ \\
\hline
\end{tabular}

Table 3. Dam with massless soil first undamped natural frequencies in $\mathrm{X}$ direction

\begin{tabular}{lllll}
\hline Mode & Frequency $(\mathrm{Hz})$ & $\mathrm{P}_{\mathrm{fi}}$ & Ratio & Mei $(\mathrm{Kg})$ \\
\hline 1 & 9.334 & 7712.6 & 1.00000 & $0.5948 \mathrm{e}+08$ \\
2 & 13.67 & -29.543 & 0.00383 & 872.768 \\
3 & 14.28 & 5749.5 & 0.74546 & $0.3305 \mathrm{e}+08$ \\
4 & 16.27 & -243.47 & 0.031567 & 59275.8 \\
5 & 16.78 & -6195.4 & 0.8032 & $0.3838 \mathrm{e}+08$ \\
\hline
\end{tabular}

Table 4. Dam-soil with soil mass first undamped natural frequencies in X direction

\begin{tabular}{lllll}
\hline Mode & Frequency $(\mathrm{Hz})$ & $\mathrm{P}_{\mathrm{fi}}$ & Ratio & Mei $(\mathrm{Kg})$ \\
\hline 1 & 6.48 & -3265.6 & 0.04513 & $0.10664 \mathrm{e}+08$ \\
2 & 6.90 & -10.623 & 0.00014 & 112.840 \\
3 & 7.40 & 184.01 & 0.00254 & 33858.1 \\
4 & 7.83 & 72359. & 1.00000 & $0.52358 \mathrm{e}+10$ \\
5 & 8.57 & -40172. & 0.55516 & $0.16137 \mathrm{e}+10$ \\
6 & 8.81 & -493.93 & 0.00682 & 243963. \\
7 & 9.16 & -36506. & 0.50451 & $0.13327 \mathrm{e}+10$ \\
8 & 9.74 & -12211. & 0.16875 & $0.14911 \mathrm{e}+09$ \\
9 & 9.83 & -941.21 & 0.01300 & 885870. \\
10 & 10.04 & -4659.5 & 0.06439 & $0.21711 \mathrm{e}+08$ \\
11 & 10.065 & -33267. & 0.45975 & $0.11067 \mathrm{e}+10$ \\
12 & 10.57 & -202.47 & 0.00279 & 40992.7 \\
13 & 10.72 & 3511.3 & 0.04852 & $0.12329 \mathrm{e}+08$ \\
14 & 11.64 & 0.9712 & 0.00001 & 0.943311 \\
15 & 11.70 & 10302. & 0.1423 & $0.1061 \mathrm{e}+09$ \\
16 & 11.94 & 995.11 & 0.0137 & 990249. \\
17 & 12.15 & 33474. & 0.4626 & $0.1120 \mathrm{e}+10$ \\
\hline
\end{tabular}


In terms of numerical values, the dam alone shows much higher frequencies than that of the dam-massless soil (12.42 Hz compared to $9.334 \mathrm{~Hz}$ for the first mode). This latter's frequencies, in turn, are also much higher than that of the dam-soil with soil mass $(6.48 \mathrm{~Hz}$ for the first mode). These results are depicted for the first 5 modes in Figure 3. Table 5 summarizes the frequencies decrease between the three models for the first 5 modes. The calculations performed highlight the need to model the foundation soil as a deformable structure, and to take into account its mass.

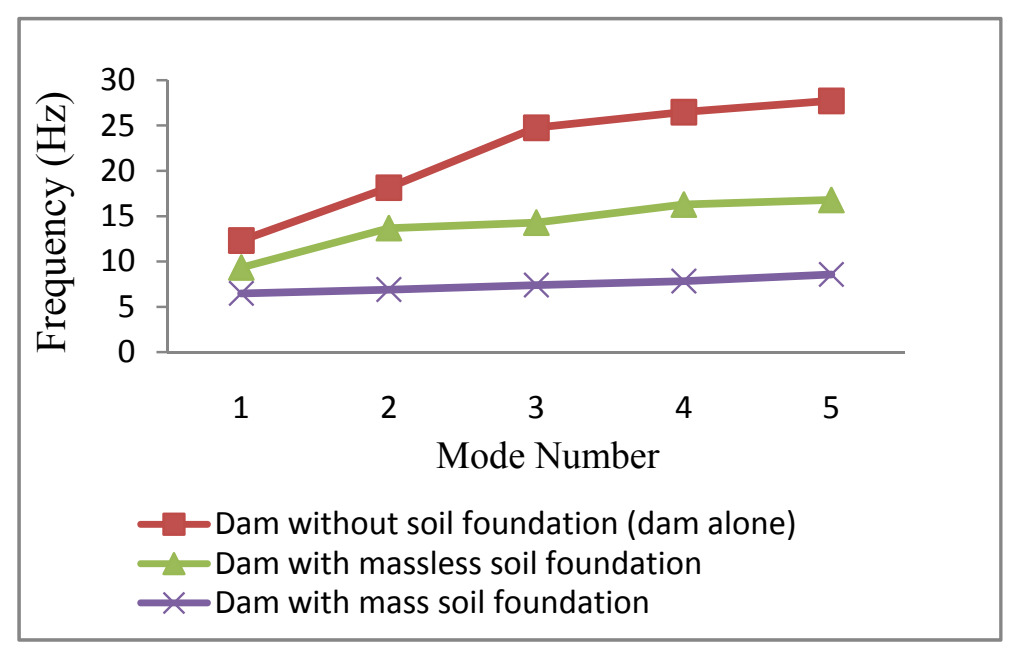

Figure 3. Undamped first 5 frequencies for the three models

Table 5. Frequencies decrease $(\%)$ between the three models

\begin{tabular}{llll}
\hline Mode & $\begin{array}{l}\text { Dam-massless soil } \\
\text { /Dam alone (\%) }\end{array}$ & $\begin{array}{l}\text { Dam-soil with mass soil } \\
\text { /Dam alone (\%) }\end{array}$ & $\begin{array}{l}\text { Dam-soil with mass soil } \\
\text { /Dam-massless soil (\%) }\end{array}$ \\
\hline 1 & 24,85 & 47,80 & 30,54 \\
2 & 26,30 & 62,79 & 49,52 \\
3 & 42,46 & 70,18 & 48,18 \\
4 & 38,64 & 70,45 & 51,84 \\
5 & 39,62 & 69,15 & 48,91 \\
\hline
\end{tabular}

\section{Damped Modal Analysis Results}

In this section, damped modal responses of the Brezina arch dam-foundation soil system are investigated. Recall that the free damped vibration equations (Reddy, 2002) are

$$
M \ddot{x}+C \dot{x}+K x=0
$$

where $M, C$ and $K$ is the mass, damping and stiffness matrix, respectively; $x, \dot{x}, \ddot{x}$ is the displacement, velocity and acceleration vector, respectively. Herein, viscous damping is assumed to be of the Raleigh form (Priscu et al., 1985):

$$
C=\alpha M+\beta K
$$

where $\alpha, \beta$ are constants referred to as mass and stiffness damping, respectively. From Eq. (3), the following relation can easily be established:

$$
\xi_{i}=\frac{\alpha}{2 \omega_{i}}+\frac{\beta \omega_{i}}{2}
$$

where $\xi_{i}$ is the viscous damping ratio to critical damping for mode $\mathrm{i}$, and $\omega_{i}$ the corresponding circular frequency. The mass damping $\alpha$, which is important for bodies resisting to wind or for submarine applications [6], is 
neglected herein. Hence, assuming $\alpha=0$, Eq. (4) is reduced to

$$
\beta=\frac{2 \xi_{i}}{\omega_{i}}
$$

which yields $\beta$ for given $\xi_{i}$ and $\omega_{i}$. Searching harmonic solutions, and making use of the Raleigh damping assumption Eq. (3) with $\alpha=0$, Eq. (2) becomes

$$
\left[(1+j \omega \beta) K-\omega^{2} M\right] x_{0}=0
$$

where $j$ is the unit complex number, $j^{2}=-1$ and $x_{0}$ the modal vector.

For the parametric study conducted herein, the viscous damping ratio $\xi$ will be $2 \%, 5 \%$ and $10 \%$, while $\omega_{i}$ will be the circular frequency of the fundamental mode (that involves the largest effective mass). The damped modal responses are calculated using the QR damped method [6]. Reported quantities are the first eigenvalues in terms of imaginary part, $\omega_{i}$, and real part, $\sigma_{i}$, the corresponding participation factor along $X$ direction, $P_{f i}$, the ratio to the maximum participation factor, Ratio, the effective mass, $M e i$, and the modal damping ratio, $\gamma_{i}$. Recall that the imaginary part $\omega_{i}$ of the eigenvalue $\rho_{i}$ is the frequency whereas the real part $\sigma_{i}$ of $\rho_{i}$ is the damping related quantity for mode $i$. The modal damping ratio, $\gamma_{i}$, is

$$
\gamma_{i}=\sigma_{i} / \sqrt{\sigma_{i}^{2}+\omega_{i}^{2}}
$$

\begin{tabular}{|c|c|c|c|c|c|c|}
\hline Mode & Im part, $\omega_{i}(\mathrm{~Hz})$ & R part, $\sigma_{i}$ & $\mathrm{P}_{\mathrm{fi}}$ & Ratio & Mei (kg) & $\gamma_{i}$ \\
\hline 1 & 12,41 & $-0,251$ & 19,267 & 0,01331 & 371,23 & $2,017 \mathrm{E}-02$ \\
\hline 2 & 18,55 & $-0,560$ & $-0,071$ & 0,00005 & $5,09 \mathrm{E}-03$ & $3,015 \mathrm{E}-02$ \\
\hline 3 & 24,81 & $-1,002$ & $-8,933$ & 0,00617 & 79,804 & 4,034E-02 \\
\hline 4 & 26,51 & $-1,143$ & $-601,100$ & 0,41524 & 361323 & $4,310 \mathrm{E}-02$ \\
\hline 5 & 27,77 & $-1,255$ & 1447,600 & 1 & $2,10 \mathrm{E}+06$ & $4,516 \mathrm{E}-02$ \\
\hline 6 & 30,34 & $-1,499$ & $-1305,700$ & 0,90195 & $1,70 \mathrm{E}+06$ & 4,934E-02 \\
\hline
\end{tabular}

Table 6. Dam alone first natural damped frequencies, viscous damping $\xi=2 \%$

Table 7. Dam with massless soil first natural damped frequencies, viscous damping $\xi=2 \%$

\begin{tabular}{|c|c|c|c|c|c|c|}
\hline Mode & Im part , $\omega_{i}(\mathrm{~Hz})$ & R part, $\sigma_{i}$ & $\mathrm{P}_{\mathrm{fi}}$ & Ratio & Mei (kg) & $\gamma_{i}$ \\
\hline 1 & 6,48 & $-0,107$ & 4453,6 & 0,00055 & $1,98 \mathrm{E}+07$ & $1,66 \mathrm{E}-02$ \\
\hline 2 & 6,90 & $-0,122$ & 812,13 & 0,00010 & 659548 & $1,76 \mathrm{E}-02$ \\
\hline 3 & 7,40 & $-0,140$ & $-1,20 \mathrm{E}+05$ & 0,01493 & $1,45 \mathrm{E}+10$ & $1,89 \mathrm{E}-02$ \\
\hline 4 & 7,84 & $-0,157$ & $-8,05 \mathrm{E}+06$ & 1,00000 & $6,49 \mathrm{E}+13$ & $2,00 \mathrm{E}-02$ \\
\hline 5 & 8,57 & $-0,188$ & $5,73 \mathrm{E}+06$ & 0,71113 & $3,28 \mathrm{E}+13$ & 2,19E-02 \\
\hline
\end{tabular}

\begin{tabular}{lllllll}
\hline Mode & Im part,$\omega_{i}(\mathrm{~Hz})$ & $\mathrm{R} \mathrm{part,}, \sigma_{i}$ & $\mathrm{P}_{\mathrm{fi}}$ & Ratio & Mei $(\mathrm{kg})$ & $\gamma_{i}$ \\
\hline 1 & 9,33 & $-0,188$ & 1240,4 & 0,01337 & $1,54 \mathrm{E}+06$ & $2,01 \mathrm{E}-02$ \\
2 & 13,67 & $-0,403$ & 1,2709 & 0,00001 & 1,61521 & $2,95 \mathrm{E}-02$ \\
3 & 14,28 & $-0,440$ & $-741,23$ & 0,00799 & 549425 & $3,08 \mathrm{E}-02$ \\
4 & 16,27 & $-0,571$ & -50129 & 0,54016 & $2,51 \mathrm{E}+09$ & $3,51 \mathrm{E}-02$ \\
5 & 16,78 & $-0,607$ & 92804 & 1,00000 & $8,61 \mathrm{E}+09$ & $3,62 \mathrm{E}-02$ \\
6 & 22,63 & $-1,107$ & -83822 & 0,90322 & $7,03 \mathrm{E}+09$ & $4,88 \mathrm{E}-02$ \\
\hline
\end{tabular}

Table 8. Dam-soil with soil mass first natural damped frequencies, viscous damping $\xi=2 \%$

Table 6, Table 7 and Table 8 list these modal quantities for the dam alone, dam-massless soil, and dam-soil with soil mass, respectively. The input damping ratio $\xi$ is $2 \%(\xi=0.02)$. Firstly, these results show that the 
frequencies are almost identical, but very slightly lower, as compared to that of the undamped modes for each model studied, e.g. $12.42 \mathrm{~Hz}$ from Table 2 and $12.41 \mathrm{~Hz}$ from Table 6 . These findings are not surprising. Consider the mass-damper-spring single degree of freedom system for which the circular frequency is

$$
\omega=\frac{\sqrt{4 k m-c^{2}}}{2 m}
$$

where $k$ is the stiffness of the spring, $m$ the mass and $c$ the damper (Reddy, 2002). It is assumed that the system is far from over damped so that in the above equation, $4 \mathrm{~km}-\mathrm{c}^{2}>0$. Eq. (8) shows that the frequency is always lower than that of the mass-spring system, and that the two frequencies are almost identical if the damping $c$ is small enough, i.e., if the system is only moderately damped. This is obviously the case for the 3D dam-soil models under study. The second remark worth noting is the negative values of $\sigma_{i}$, indicating that the dam-soil system is stable. This is expected as the analogy can be made again with the simple system for which

$$
\sigma=-\frac{c}{2 m}
$$

It should be noted that under the Raleigh damping assumption with $\alpha=0$, the damping $c$, in the above mass-damper-spring system, becomes $c=\beta k$. Recall that $\sigma$ and $\omega$ are the real and imaginary part, respectively, of the roots of the characteristic equation (Reddy, 2002). Lastly, Table 6 shows that adding damping to the dam-soil system switches the fundamental mode. For example, mode number five is now the fundamental mode for the dam alone (see Table 6) while without damping, the fundamental mode is number one (see Table 2).

For $\xi=0.02$, Figure 4 depicts the frequencies decrease from the dam alone to the dam-soil with soil mass model for the first 5 modes, and Figure 5 illustrates the decrease of the damping related quantity $\alpha_{i}$. Like the comments made in the preceding section, qualitatively, the frequencies decrease between the three models can be explained from Equation (8). Also, from Equation (9) and $c=\beta k$, the damping decrease, in absolute value, from the dam alone to the dam-soil with soil mass model is obvious. Finally, this decrease in percentage is summarized in Table 9 and Table 10.

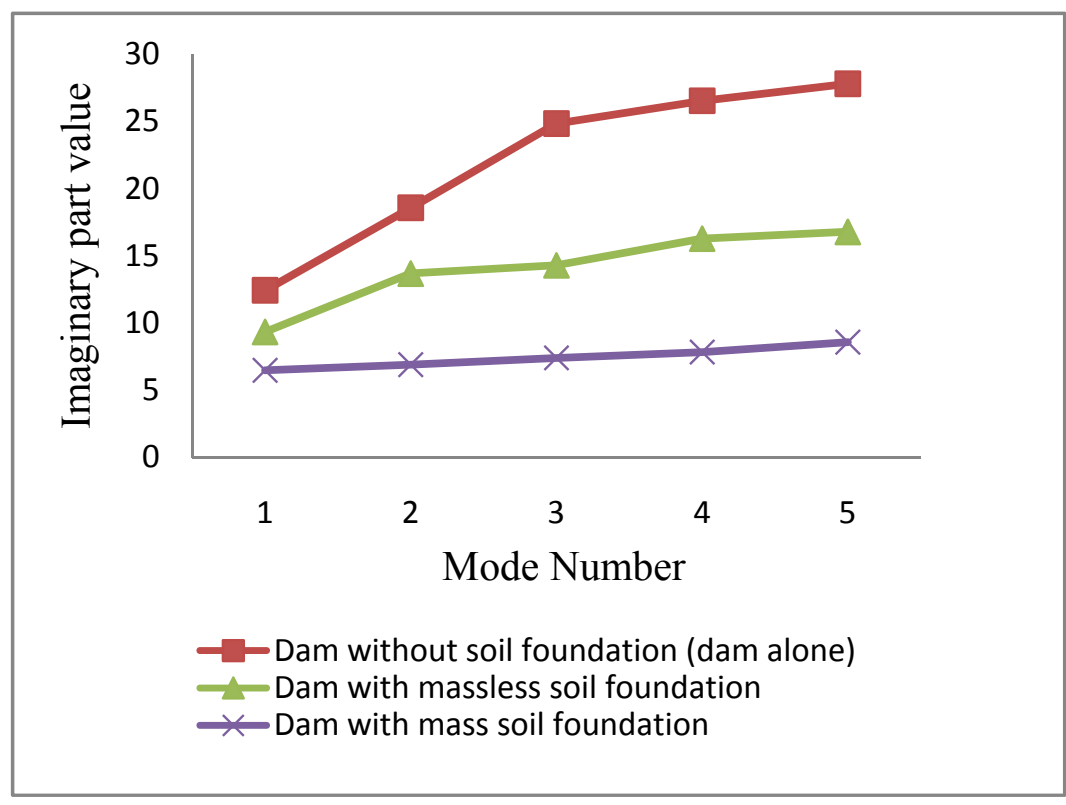

Figure 4. Damped first 5 frequencies for the three models, viscous damping $\xi=2 \%$ 


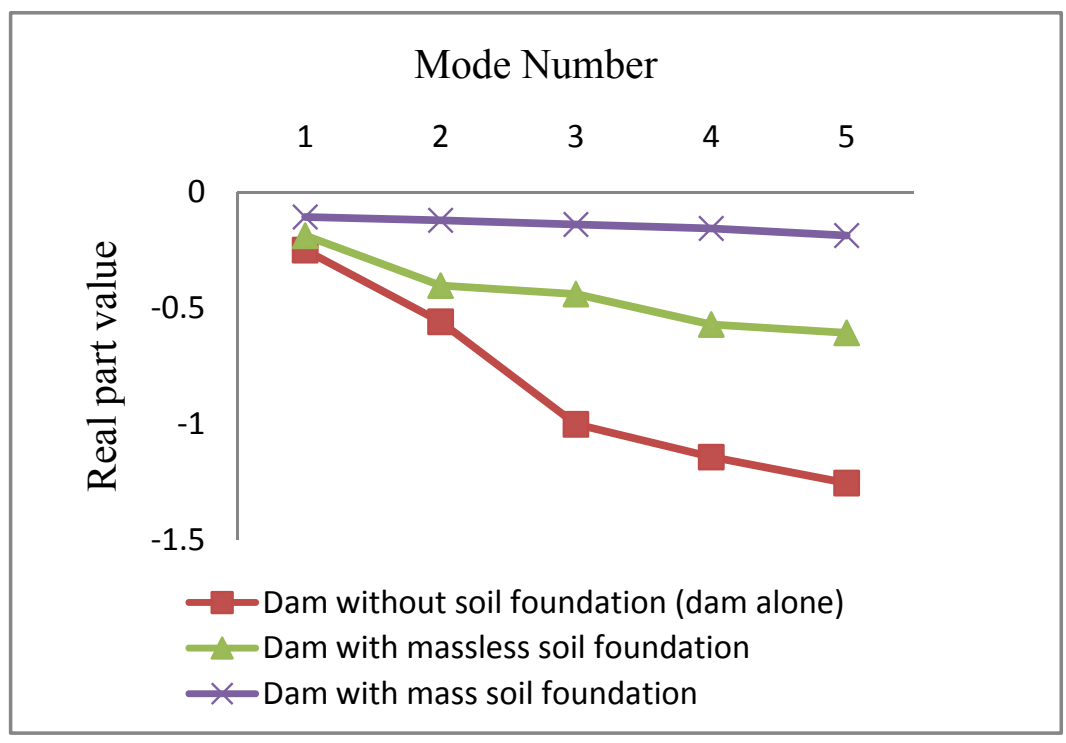

Figure 5. First 5 damping related quantities for the three models, viscous damping $\xi=2 \%$

Table 9. Frequencies decrease (\%) between the three models, viscous damping $\xi=2 \%$

\begin{tabular}{llll}
\hline Mode & $\begin{array}{l}\text { Dam-massless soil } \\
\text { /Dam alone (\%) }\end{array}$ & $\begin{array}{l}\text { Dam-soil with soil mass } \\
\text { /Dam alone (\%) }\end{array}$ & $\begin{array}{l}\text { Dam-soil with soil mass } \\
\text { /Dam-massless soil (\%) }\end{array}$ \\
\hline 1 & 24,85 & 47,80 & 30,54 \\
2 & 26,30 & 62,79 & 49,51 \\
3 & 42,44 & 70,17 & 48,17 \\
4 & 38,62 & 70,43 & 51,83 \\
5 & 39,60 & 69,13 & 48,89 \\
\hline
\end{tabular}

Table 10. Damped related quantities in absolute values decrease (\%) between the three models, viscous damping $\xi=2 \%$

\begin{tabular}{llll}
\hline Mode & $\begin{array}{l}\text { Dam-massless soil } \\
\text { /Dam alone (\%) }\end{array}$ & $\begin{array}{l}\text { Dam-soil with mass soil } \\
\text { /Dam alone (\%) }\end{array}$ & $\begin{array}{l}\text { Dam-soil with mass soil } \\
\text { /Dam-massless soil (\%) }\end{array}$ \\
\hline 1 & 25,07 & 57,16 & 42,83 \\
2 & 27,93 & 78,23 & 69,80 \\
3 & 56,07 & 86,02 & 68,18 \\
4 & 50,05 & 86,27 & 72,52 \\
5 & 51,63 & 85,04 & 69,07 \\
\hline
\end{tabular}

Similar results for the input damping ratio $\xi$ of $5 \%$ and $10 \%$ are reported in Tables $11-13$ and Tables 16-18, respectively. From these results, same comments as for $\xi=2 \%$ can be made although the differences in frequencies are slightly more pronounced with respect to that of the undamped modes: the larger the damping ratio, the bigger the differences. This is clearly supported by Equation (8). Figure 6, Figure 7, Figure 8 and Figure 9 depict the frequency and damping related quantity decrease between the three models for $\xi=0.05$ and $\xi=0.1$, respectively. Tables 14-15 and Tables 19-20 summarize theses evolutions in percentage. 


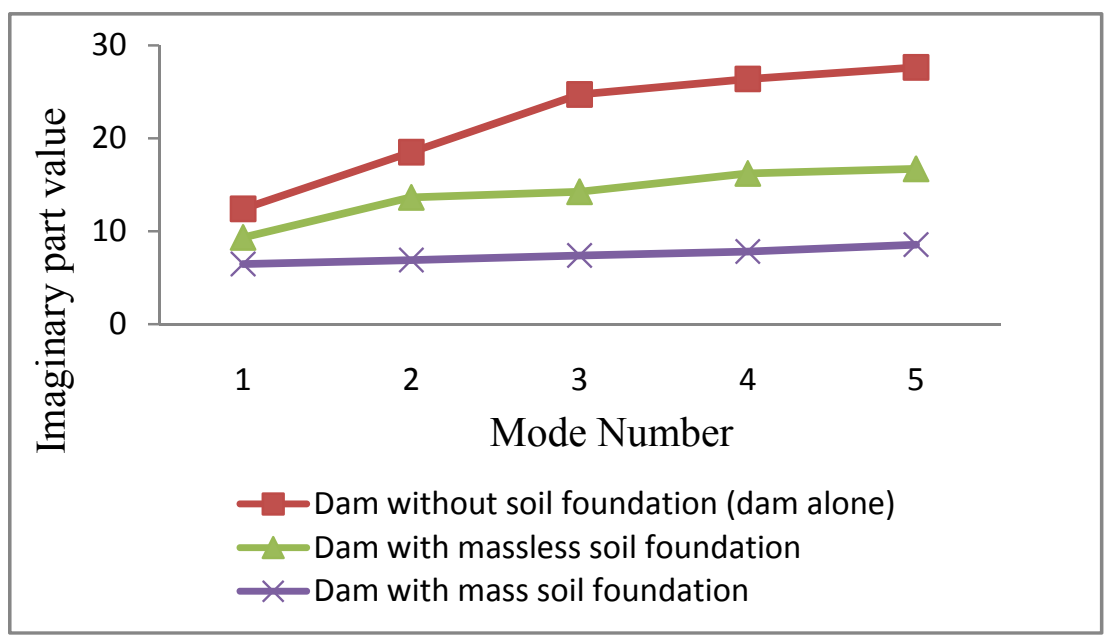

Figure 6. First 5 damped frequencies for the three models, viscous damping $\xi=5 \%$

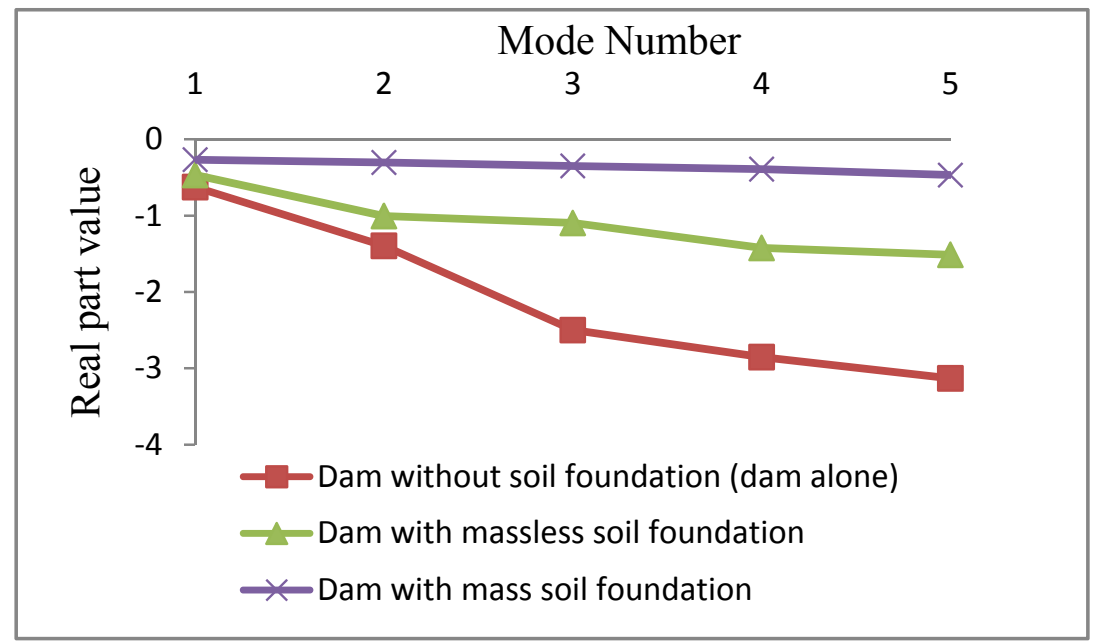

Figure 7. First 5 damped related quantities for the three models, viscous damping $\xi=5 \%$

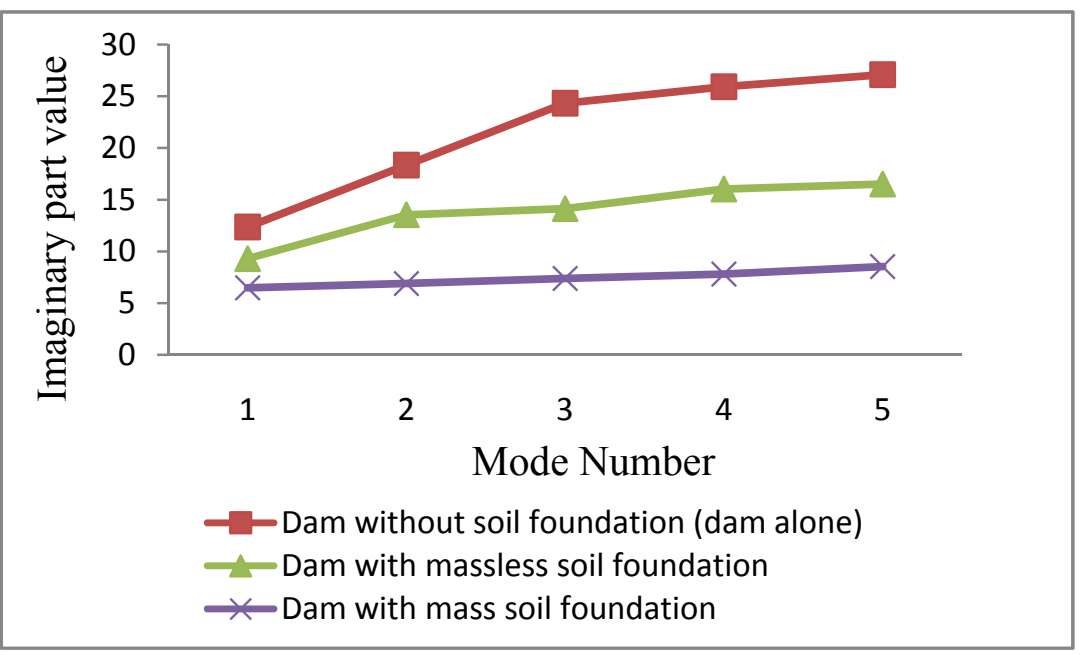

Figure 8. Damped first 5 frequencies for the three models, viscous damping $\xi=10 \%$ 


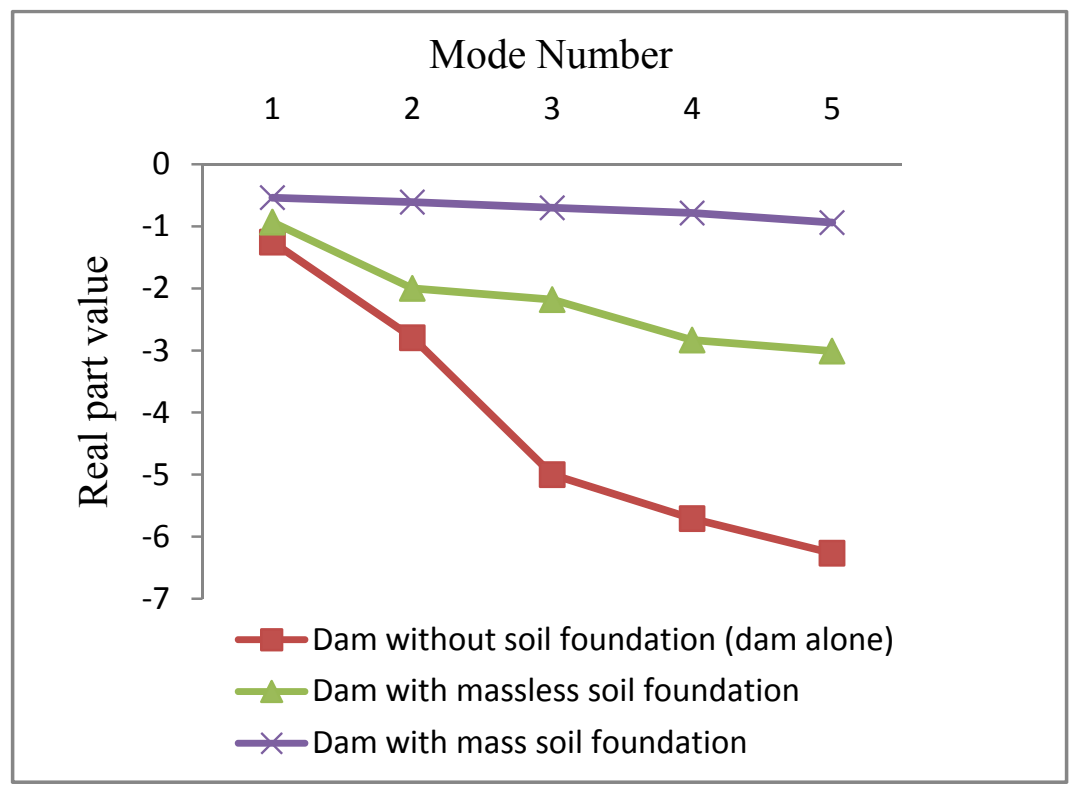

Figure 9. First 5 damped related quantities for the three models, viscous damping $\xi=10 \%$

Table 11. Dam alone first natural damped frequencies, viscous damping $\xi=5 \%$

\begin{tabular}{lllllll}
\hline Mode & Im part, $\omega_{i}(\mathrm{~Hz})$ & $\mathrm{R} \mathrm{part,} \sigma_{i}$ & $\mathrm{P}_{\mathrm{fi}}$ & Ratio & Mei $(\mathrm{kg})$ & $\gamma_{i}$ \\
\hline 1 & 12.40 & -0.625 & -38.605 & 0.01331 & 1490.36 & $0.503 \mathrm{e}-01$ \\
2 & 18.50 & -1.396 & 0.143 & 0.00005 & $0.204 \mathrm{e}-01$ & $0.503 \mathrm{e}-01$ \\
3 & 24.70 & -2.499 & 17.899 & 0.00617 & 320.386 & $0.752 \mathrm{e}-01$ \\
4 & 26.37 & -2.853 & 1204.4 & 0.41524 & $0.145 \mathrm{e}+07$ & $0.752 \mathrm{e}-01$ \\
5 & 27.62 & -3.132 & -2900.5 & 1.000 & $0.841 \mathrm{e}+07$ & 0.100 \\
6 & 30.14 & -3.740 & 2616.1 & 0.90195 & $0.684 \mathrm{e}+07$ & 0.100 \\
\hline
\end{tabular}

Table 12. Dam with massless soil first natural damped frequencies, viscous damping $\xi=5 \%$

\begin{tabular}{|c|c|c|c|c|c|c|}
\hline Mode & $\operatorname{Im}$ part,$\omega_{i}(\mathrm{~Hz})$ & R part, $\sigma_{i}$ & $\mathrm{P}_{\mathrm{fi}}$ & Ratio & Mei (kg) & $\gamma_{i}$ \\
\hline 1 & 9.32 & -0.468 & 457.64 & 0.01336 & 209432. & $0.501 \mathrm{e}-01$ \\
\hline 2 & 13.64 & -1.005 & 0.46888 & 0.000014 & 0.219844 & $0.734 \mathrm{e}-01$ \\
\hline 3 & 14.24 & -1.096 & -273.46 & 0.00798 & 74781.7 & $0.767 \mathrm{e}-01$ \\
\hline 4 & 16.21 & -1.423 & -18494 & 0.54016 & $0.342 \mathrm{e}+09$ & $0.874 \mathrm{e}-01$ \\
\hline 5 & 16.71 & -1.513 & 34238. & 1.00000 & $0.117 \mathrm{e}+10$ & $0.901 \mathrm{e}-01$ \\
\hline 6 & 22.49 & -2.758 & -30924 & 0.90322 & $0.956 \mathrm{e}+09$ & 0.121 \\
\hline
\end{tabular}

Table 13. Dam-soil with soil mass soil first natural damped frequencies, viscous damping $\xi=5 \%$

\begin{tabular}{|c|c|c|c|c|c|c|}
\hline Mode & Im part, $\omega_{i}(\mathrm{~Hz})$ & R part, $\sigma_{i}$ & $\mathrm{P}_{\mathrm{fi}}$ & Ratio & Mei (kg) & $\gamma_{i}$ \\
\hline 1 & 6.47 & -0.268 & 229.81 & 0.0005 & 52811.6 & $0.413 e-01$ \\
\hline 2 & 6.89 & -0.304 & 41.906 & 0.0001 & 1756.11 & $0.440 \mathrm{e}-01$ \\
\hline 3 & 7.39 & -0.349 & -6204.3 & 0.015 & $0.3849 \mathrm{e}+08$ & $0.472 \mathrm{e}-01$ \\
\hline 4 & 7.82 & -0.391 & $-0.415 \mathrm{e}+06$ & 1.000 & $0.1726 \mathrm{e}+12$ & $0.499 \mathrm{e}-01$ \\
\hline 5 & 8.56 & -0.469 & $0.295 \mathrm{e}+06$ & 0.711 & $0.8733 \mathrm{e}+11$ & $0.546 \mathrm{e}-01$ \\
\hline
\end{tabular}


Table 14. Frequencies decrease (\%) between the three models, viscous damping $\xi=5 \%$

\begin{tabular}{llll}
\hline Mode & $\begin{array}{l}\text { Dam-massless soil } \\
\text { /Dam alone (\%) }\end{array}$ & $\begin{array}{l}\text { Dam-soil with mass soil } \\
\text { /Dam alone (\%) }\end{array}$ & $\begin{array}{l}\text { Dam-soil with mass soil } \\
\text { /Dam-massless soil (\%) }\end{array}$ \\
\hline 1 & 24,85 & 47,78 & 30,52 \\
2 & 26,29 & 62,72 & 49,43 \\
3 & 42,33 & 70,06 & 48,08 \\
4 & 38,52 & 70,32 & 51,72 \\
5 & 39,48 & 69,00 & 48,78 \\
\hline
\end{tabular}

Table 15. Damped related quantities in absolute values decrease (\%) between the three models, viscous damping $\xi=5 \%$

\begin{tabular}{llll}
\hline Mode & $\begin{array}{l}\text { Dam-massless soil } \\
\text { /Dam alone (\%) }\end{array}$ & $\begin{array}{l}\text { Dam-soil with mass soil } \\
\text { /Dam alone (\%) }\end{array}$ & $\begin{array}{l}\text { Dam-soil with mass soil } \\
\text { /Dam-massless soil (\%) }\end{array}$ \\
\hline 1 & 25,14 & 57,13 & 42,73 \\
2 & 27,99 & 78,21 & 69,75 \\
3 & 56,11 & 86,010 & 68,12 \\
4 & 50,09 & 86,26 & 72,47 \\
5 & 51,67 & 85,023 & 69,01 \\
\hline
\end{tabular}

Table 16. Dam alone first natural damped frequencies, viscous damping $\xi=10 \%$

\begin{tabular}{lllllll}
\hline Mode & Im part,$\omega_{i}(\mathrm{~Hz})$ & $\mathrm{R} \mathrm{part,} \sigma_{i}$ & $\mathrm{P}_{\mathrm{fi}}$ & Ratio & Mei $(\mathrm{kg})$ & $\gamma_{i}$ \\
\hline 1 & 12.35 & -1.250 & -35.469 & 0.013 & 1258.08 & 0.10 \\
2 & 18.34 & -2.792 & 0.1314 & 0.00004 & $0.172 \mathrm{e}-01$ & 0.15 \\
3 & 24.32 & -4.999 & 16.445 & 0.0061 & 270.452 & 0.201 \\
4 & 25.91 & -5.706 & 1106.6 & 0.4152 & $0.1224 \mathrm{e}+07$ & 0.215 \\
5 & 27.08 & -6.264 & -2664.9 & 1.000 & $0.71019 \mathrm{e}+07$ & 0.225 \\
6 & 29.44 & -7.480 & 2403.6 & 0.901 & $0.57774 \mathrm{e}+07$ & 0.246 \\
\hline
\end{tabular}

Table 17. Dam with massless soil first natural damped frequencies, viscous damping $\xi=10 \%$

\begin{tabular}{lllllll}
\hline Mode & Im part, $\omega_{i}(\mathrm{~Hz})$ & $\mathrm{R} \mathrm{part,} \sigma_{i}$ & $\mathrm{P}_{\mathrm{fi}}$ & Ratio & Mei $(\mathrm{kg})$ & $\gamma_{i}$ \\
\hline 1 & 9.28 & -0.930 & -171.52 & 0.013366 & 29420.3 & $0.997 \mathrm{e}-01$ \\
2 & 13.53 & -1.998 & -0.17574 & 0.000014 & $0.308 \mathrm{e}-01$ & 0.146 \\
3 & 14.12 & -2.181 & 102.49 & 0.007987 & 10505.1 & 0.152 \\
4 & 16.03 & -2.830 & 6931.6 & 0.540160 & $0.480 \mathrm{e}+08$ & 0.173 \\
5 & 16.51 & -3.009 & -12832. & 1.00 & $0.164 \mathrm{e}+09$ & 0.179 \\
6 & 21.98 & -5.485 & 11591. & 0.903 & $0.134 \mathrm{e}+09$ & 0.242 \\
\hline
\end{tabular}

Table 18. Dam-soil with soil mass first natural damped frequencies, viscous damping $\xi=10 \%$

\begin{tabular}{lllllll}
\hline Mode & Im part, $\omega_{i}(\mathrm{~Hz})$ & $\mathrm{R} \mathrm{part,} \sigma_{i}$ & $\mathrm{P}_{\mathrm{fi}}$ & Ratio & Mei $(\mathrm{kg})$ & $\gamma_{i}$ \\
\hline 1 & 6.46 & -0.536 & -642.87 & 0.0005 & 413279. & $0.826 \mathrm{e}-01$ \\
2 & 6.87 & -0.608 & -117.23 & 0.0001 & 13742.5 & $0.8807 \mathrm{e}-1$ \\
3 & 7.37 & -0.699 & 17356. & 0.0149 & $0.3012 \mathrm{e}+09$ & $0.9444 \mathrm{e}-01$ \\
4 & 7.79 & -0.783 & $0.11625 \mathrm{e}+07$ & 1.0000 & $0.1351 \mathrm{e}+13$ & $0.9998 \mathrm{e}-01$ \\
5 & 8.52 & -0.938 & $-0.8267 \mathrm{e}+06$ & 0.7111 & $0.6834 \mathrm{e}+12$ & 0.1093 \\
\hline
\end{tabular}


Table 19. Frequencies decrease (\%) between the three models, damping $\xi=10 \%$

\begin{tabular}{llll}
\hline Mode & $\begin{array}{l}\text { Dam-massless soil } \\
\text { /Dam alone (\%) }\end{array}$ & $\begin{array}{l}\text { Dam-soil with soil mass } \\
\text { /Dam alone (\%) }\end{array}$ & $\begin{array}{l}\text { Dam-soil with soil mass } \\
\text { /Dam-massless soil (\%) }\end{array}$ \\
\hline 1 & 24,84 & 47,72 & 30,43 \\
2 & 26,25 & 62,51 & 49,17 \\
3 & 41,94 & 69,69 & 47,80 \\
4 & 38,13 & 69,89 & 51,34 \\
5 & 39,03 & 68,53 & 48,38 \\
\hline
\end{tabular}

Table 20. Damped related quantities in absolute value decrease (\%) between the three models, viscous damping $\xi=10 \%$

\begin{tabular}{llll}
\hline Mode & $\begin{array}{l}\text { Dam-massless soil } \\
\text { /Dam alone (\%) }\end{array}$ & $\begin{array}{l}\text { Dam-soil with soil mass } \\
\text { /Dam alone (\%) }\end{array}$ & $\begin{array}{l}\text { Dam-soil with soil mass } \\
\text { /Dam-massless soil (\%) }\end{array}$ \\
\hline 1 & 25,57 & 57,13 & 42,40 \\
2 & 28,42 & 78,21 & 69,57 \\
3 & 56,37 & 86,01 & 67,93 \\
4 & 50,38 & 86,26 & 72,31 \\
5 & 51,95 & 85,02 & 68,83 \\
\hline
\end{tabular}

Influences of the viscous damping ratio $\xi$ on the frequencies and the damping related quantity are summarized in Figures 10-11 and Tables 21-22 for the dam without soil model, Figure 12-13 and Tables 23-24 for the dam with massless soil model, and Figures 14-15 and Tables 25-26 for the dam-soil with soil mass model.

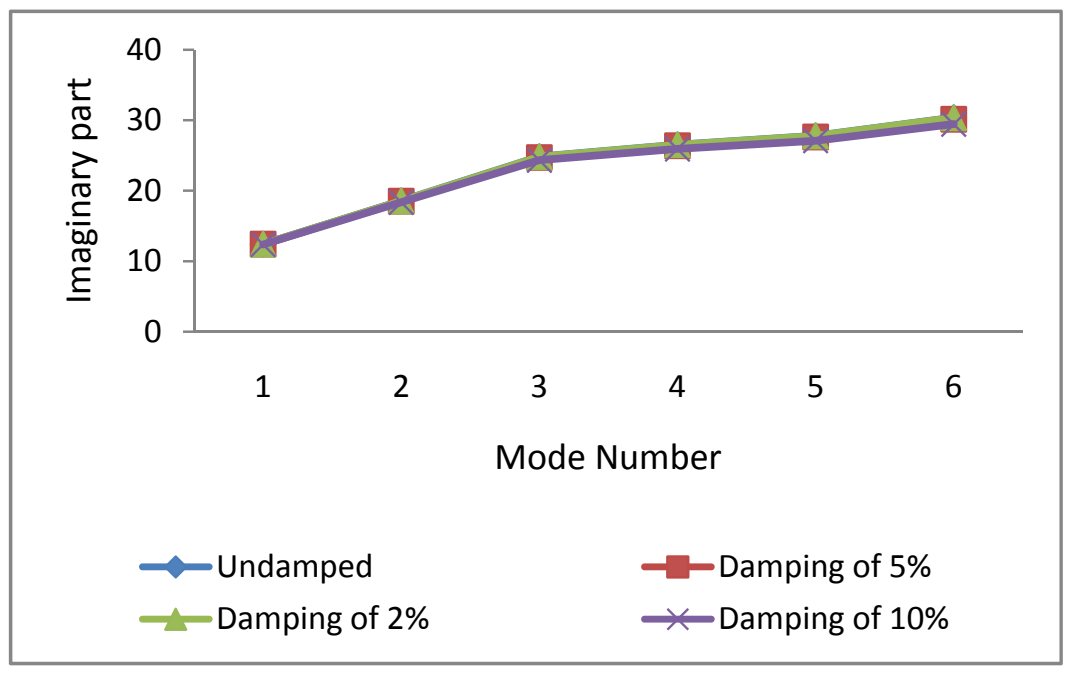

Figure 10. Influence of viscous damping $\xi$ on the frequencies for the dam alone model 


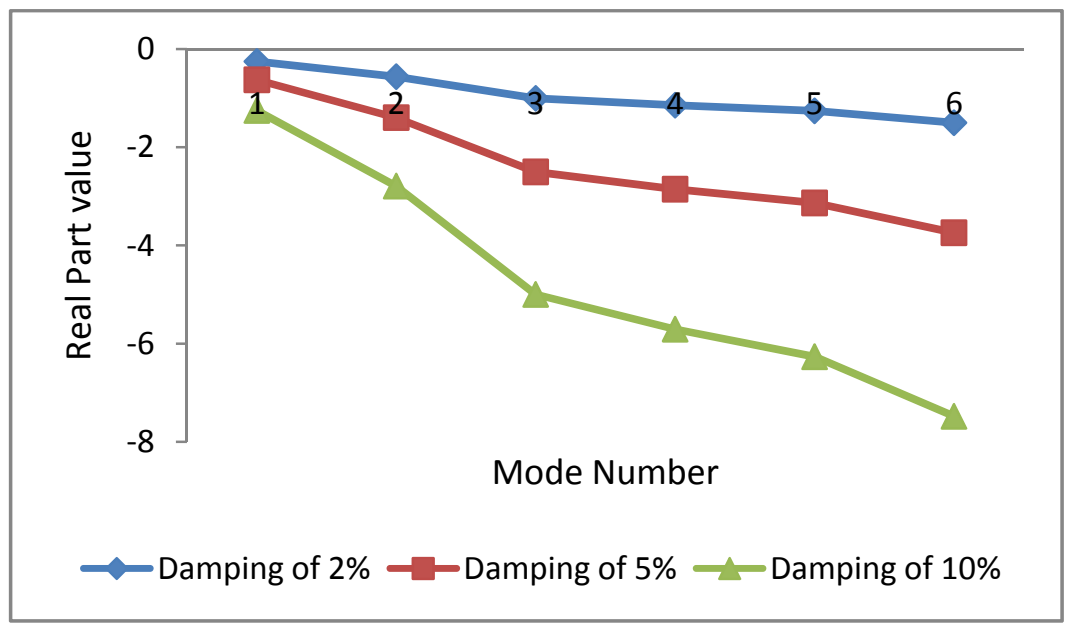

Figure 11. Influence of viscous damping $\xi$ on the damping related quantities for the dam alone model

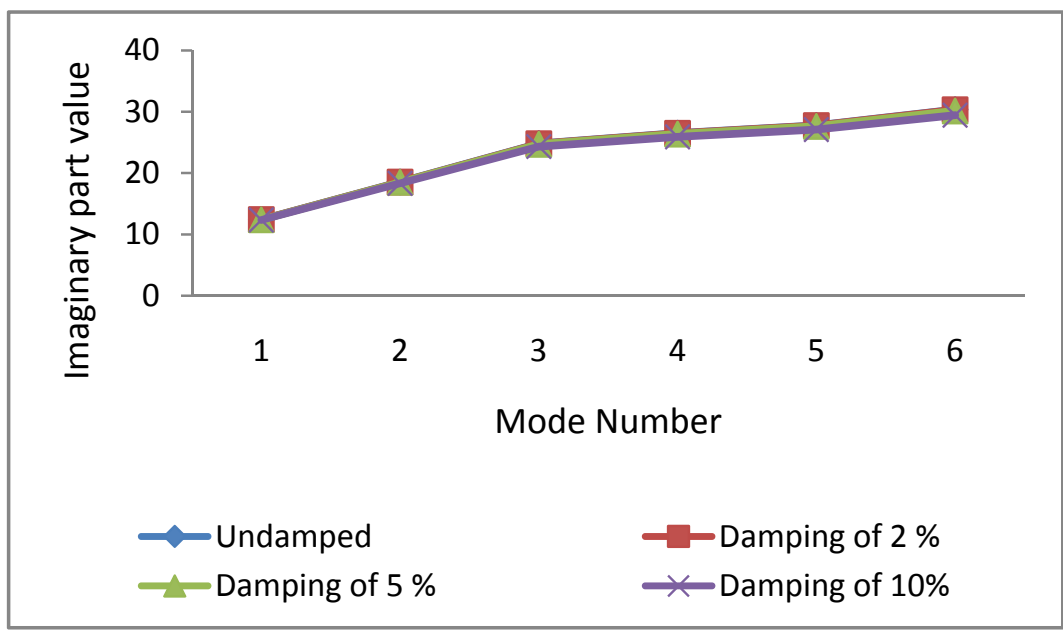

Figure 12. Influence of viscous damping $\xi$ on the frequencies for the dam with massless soil model

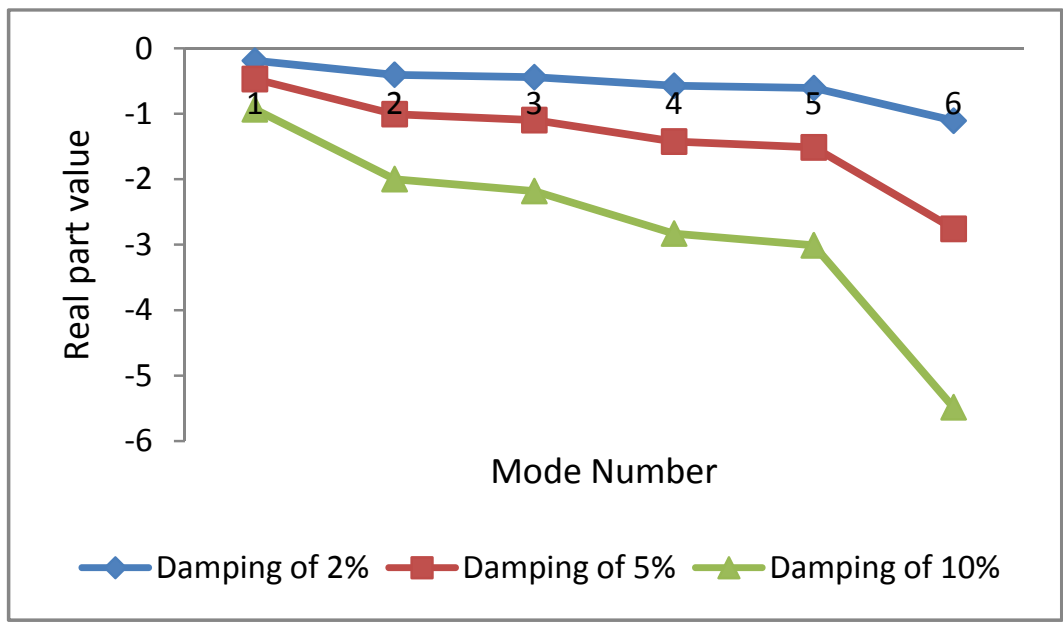

Figure 13. Influence of viscous damping $\xi$ on the damping related quantities for the dam with massless soil model 


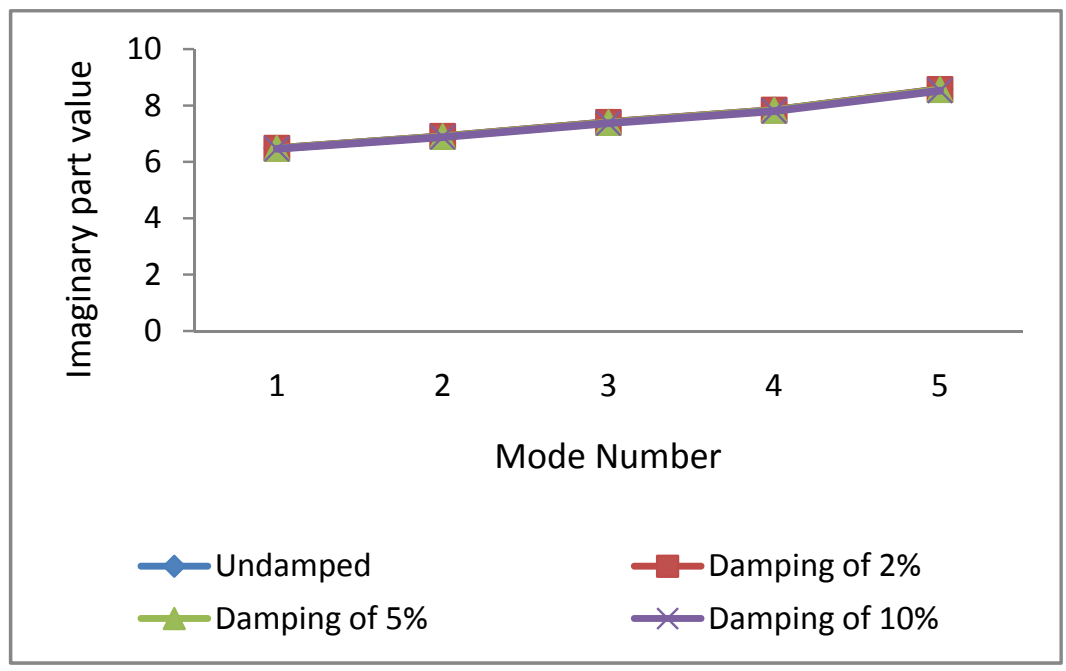

Figure 14. Influence of viscous damping $\xi$ on the frequencies for the dam-soil with soil mass model

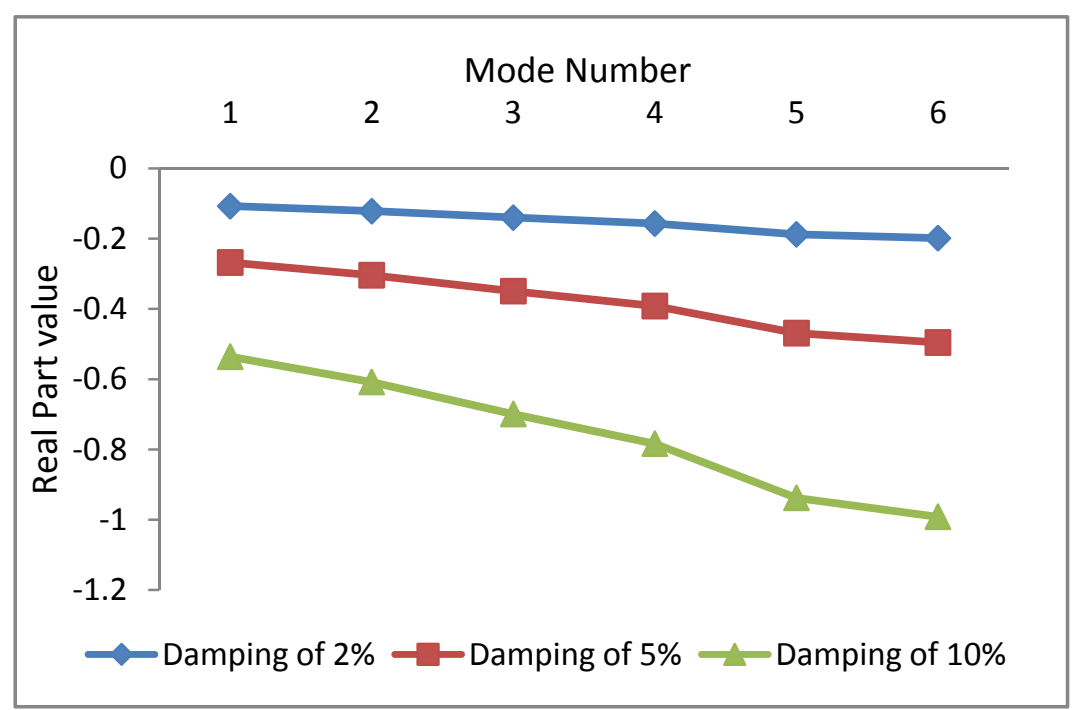

Figure 15. Influence of viscous damping $\xi$ on the damping related quantities for the dam-soil with soil mass model

Table 21. Influence of viscous damping $\xi$ on the frequencies for the dam alone model

\begin{tabular}{lllll}
\hline Mode & Undamped & Damping of 2\% & Damping of 5\% & Damping of 10\% \\
\hline 1 & 12,42 & 12,41 & 12,40 & 12,35 \\
2 & 18,56 & 18,55 & 18,50 & 18,34 \\
3 & 24,83 & 24,81 & 24,70 & 24,32 \\
4 & 26,53 & 26,50 & 26,37 & 25,91 \\
5 & 27,80 & 27,77 & 27,62 & 27,08 \\
6 & 30,37 & 30,34 & 30,14 & 29,44 \\
\hline
\end{tabular}


Table 22. Influence of viscous damping $\xi$ on the damping related quantities for the dam alone model

\begin{tabular}{llll}
\hline Mode & Damping of 2\% & Damping of 5\% & Damping of $10 \%$ \\
\hline 1 & $-0,250$ & $-0,625$ & $-1,250$ \\
2 & $-0,559$ & $-1,396$ & $-2,792$ \\
3 & $-1,001$ & $-2,499$ & $-4,999$ \\
4 & $-1,143$ & $-2,853$ & $-5,706$ \\
5 & $-1,255$ & $-3,132$ & $-6,264$ \\
6 & $-1,499$ & $-3,740$ & $-7,480$ \\
\hline
\end{tabular}

Table 23. Influence of viscous damping $\xi$ on the frequencies for the dam with massless soil model

\begin{tabular}{lllll}
\hline Mode & Undamped & Damping of 2\% & Damping of 5\% & Damping of 10\% \\
1 & 9,33 & 9,33 & 9,32 & 9,28 \\
2 & 13,67 & 13,67 & 13,64 & 13,53 \\
3 & 14,28 & 14,28 & 14,24 & 14,12 \\
4 & 16,27 & 16,26 & 16,21 & 16,03 \\
5 & 16,78 & 16,77 & 16,71 & 16,51 \\
6 & 22,66 & 22,63 & 22,49 & 21,98 \\
\hline
\end{tabular}

Table 24. Influence of viscous damping $\xi$ on the damping related quantities for the dam with massless soil model

\begin{tabular}{llll}
\hline Mode & Damping of 2\% & Damping of 5\% & Damping of $10 \%$ \\
\hline 1 & $-0,187$ & $-0,468$ & $-0,930$ \\
2 & $-0,403$ & $-1,005$ & $-1,998$ \\
3 & $-0,440$ & $-1,096$ & $-2,181$ \\
4 & $-0,571$ & $-1,423$ & $-2,830$ \\
5 & $-0,607$ & $-1,513$ & $-3,009$ \\
6 & $-1,106$ & $-2,758$ & $-5,485$ \\
\hline
\end{tabular}

Table 25. Influence of viscous damping $\xi$ on the frequencies for the dam-soil with soil mass model

\begin{tabular}{lllll}
\hline Mode & Undamped & Damping of 2\% & Damping of 5\% & Damping of $10 \%$ \\
\hline 1 & 6,48 & 6,48 & 6,47 & 6,46 \\
2 & 6,90 & 6,90 & 6,89 & 6,87 \\
3 & 7,40 & 7,40 & 7,39 & 7,37 \\
4 & 7,83 & 7,83 & 7,82 & 7,79 \\
5 & 8,57 & 8,57 & 8,56 & 8,52 \\
\hline
\end{tabular}

Table 26. Influence of viscous damping $\xi$ on the damping related quantities for the dam-soil with soil mass model

\begin{tabular}{llll}
\hline Mode & Damping of 2\% & Damping of 5\% & Damping of $10 \%$ \\
\hline 1 & $-0,107$ & $-0,268$ & $-0,536$ \\
2 & $-0,121$ & $-0,304$ & $-0,608$ \\
3 & $-0,140$ & $-0,349$ & $-0,699$ \\
4 & $-0,156$ & $-0,391$ & $-0,783$ \\
5 & $-0,187$ & $-0,469$ & $-0,938$ \\
6 & $-0,198$ & $-0,495$ & $-0,991$ \\
\hline
\end{tabular}


Quantitatively, results reported in this section point out, again, the importance of taking into account the soil with its mass. For any of the damping ratio under study, the dam alone shows significantly higher frequencies than that of the dam-massless soil. This latter's frequencies are also much higher than that of the dam-soil with soil mass. The damping values calculated are also much lower in absolute value from the dam-soil with soil mass than that from the other two models. The results reported also show that adding only a small damping ratio, e.g. $\xi=0.02$, to the dam-soil model reduces the number of modes needed to obtain $90 \%$ of the system's total mass. For example, for the undamped dam alone model, 17 modes are needed to reach $91.73 \%$ of the total mass, whereas for its damped counterpart with $\xi=0.02,6$ modes are sufficient to reach $96.9 \%$ of the total mass. This feature is of practical importance as it reduces the CPU time for a further analysis based on the modal superposition method such as a spectrum analysis or a modal superposition transient response analysis.

\section{Conclusions}

Modal responses of the Brezina dam-foundation soil system are calculated using the finite element software, ANSYS. The following conclusions are drawn based on the numerical experiments conducted herein:

1) For the study of the dam-soil system, the foundation soil should be modeled as a deformable structure with its mass taken into account. The natural frequencies of either undamped or damped modes are much lower from the dam-soil with soil mass than that from the dam alone, and significantly lower than that from the dam-massless soil model. Modeling the soil with its mass also affects the mode shape by changing the fundamental mode position.

2) Likewise, for any of the damping ratio under study, the damping related values calculated are significantly lower, in absolute value, from the dam-soil with soil mass than that from the dam-massless soil, and much lower than that from the dam alone model.

3) Adding only a small damping ratio of $2 \%$ to Brezina dam-soil model reduces the number of modes needed, as compared to the undamped model, to obtain $90 \%$ of the system's total mass. This is of practical importance as it reduces the CPU time for a further analysis based on the modal superposition method, such as a modal superposition transient response analysis, which will be undertaken following the present work.

\section{References}

ANSYS. (2007). ANSYS User's Manual, ANSYS Theory Manual. Version 11.0, 2007.

Bayraktar, A, Hancer, E., \& Akkose, M. (2005). Influence of base-rock characteristics on the stochastic dynamic response of dam-reservoir-foundation systems. Engineering Structures, 27(10), 1498-1508. http://dx.doi.org/10.1016/j.engstruct.2005.05.004

Dimitris, P, Dietz, M., Wood, D. M., Clouteau, D., \& Modaressi, A. (2008). Numerical simulation of dynamic soil-structure interaction in shaking table testing. Soil dynamics and earthquake Engineering, 28, 453-467. http://dx.doi.org/10.1016/j.soildyn.2007.07.011

Dreher, K. J. (1980). Seismic analysis and design considerations for Concrete dams. Proceeding of a Conference on Dams and Earthquake held at the Institution of Civil Engineers.

Leger. P., \& Boughoufalah, M. (1989). Earthquake input mechanisms for time domain analysis of dam-foundation systems. Engineering Structures, 11, 37-46. http://dx.doi.org/10.1016/0141-0296(89)90031-X

Priscu, R., Popovici, A., Stematiu, D., \& Stere, C. (1982). Earthquake Engineering for Large Dams (2nd revised ed.). Editura Academiei and John Wiley \& Sons.

Reddy, J. N. (2002). Energy Principles and Variational Methods in Applied Mechanics (2nd ed.). New York: John Wiley \& Sons.

Shabana, A. A. (1995). Theory of Vibration - An Introduction. Mechanical Engineering Series (2nd ed.). Springer.

Tepes, O. F., \& Gelmambet, S. (2010). Evaluation of damping in dynamic analysis of structures. International journal of mathematical models and methods in applied sciences, 2(4), 124-131. 